\title{
In Situ Assessment of the Setting of Tricalcium Silicate-based Sealers Using a Dentin Pressure Model
}

\author{
Maria Xuereb, BChD, MSc, * Paul Vella, BSc (Hons), * Denis Damidot, PbD, HDR, ${ }^{\dagger}$ \\ Charles V. Sammut, BA (Educ), BSc (Hons), PbD, CPbys, M Inst P, M IEEE, M ICOH, ${ }^{\ddagger}$ \\ and Josette Camilleri, BChD, MPhil, PhD, FADM, FIMMM*
}

\section{Ahstract}

Introduction: EndoSequence BC Sealer (Brasseler, Savannah, GA) is a premixed tricalcium silicate-based root canal sealer that requires moisture from the root dentin to hydrate. The aim of this study was to investigate the setting of EndoSequence BC Sealer and other sealers in contact with human dentin in a simulated clinical environment. Methods: EndoSequence BC Sealer, MTA Fillapex (Angelus, Londrina, Brazil), Septodont Sealer (Septodont, Saint Maur-des-Fosses, France), and Apexit Plus (Ivoclar, Schaan, Lichtenstein) were assessed. Caries-free lower premolars extracted for orthodontic purposes in patients aged 13-16 years were standardized to a $10-\mathrm{mm}$ root length and were filled with test sealers and set up in a dentin pressure model for 14 days. In addition, set sealers immersed in physiologic solution for 14 days were also assessed. The set materials in solution and materials retrieved from the dentin pressure setup were characterized by scanning electron microscopy and X-ray diffraction analysis. The setting time and radiopacity were assessed using ISO 6876:2002 specifications. Furthermore, mineral ion leaching was evaluated by inductively coupled plasma mass spectrometry. Results: All the sealers tested exhibited formation of a calcium phosphate phase when in contact with physiologic solution. Septodont Sealer and Apexit Plus did not exhibit the formation of a calcium phosphate phase in the dentin pressure setup. The fluid in the system was enough to allow the setting of EndoSequence BC Sealer, which did not set in a dry environment. All materials leached calcium with the Septodont Sealer, exhibiting double the calcium ion leaching compared with EndoSequence BC Sealer. Conclusions: Using the dentinal fluid pressure system resulted in an adequate flow of dentinal fluid that allowed EndoSequence BC Sealer to set inside the root canal. Although the sealers tested were tricalcium silicate based, the hydration reaction and bioactivity in the presence of dentinal fluid were different to hydration in vitro. Thus, clinically, material bioactivity cannot be assumed. (J Endod 2015;41:111-124)

\section{Key Words}

Apexit Plus, dentin pressure model, EndoSequence BC sealer, hydration, MTA Fillapex, Septodont Sealer, setting

Tricalcium silicate, also known as alite, with the chemical formula $\mathrm{Ca}_{3} \mathrm{SiO}_{5}$ is one of the main components of Portland cement, mineral trioxide aggregate (MTA), Biodentine (Septodont, Saint Maur-des-Fosses, France), and Bioaggregate (Verio Dena, Vancouver, Canada). Portland cement, which is the main constituent of MTA, is made up of $74 \%$ of tricalcium silicate (1), whereas MTA contains approximately $52 \%$ and $66 \%$ of unhydrated tricalcium silicate for white ProRoot MTA (Dentsply Tulsa, Johnson City, TN) (1, 2) and white MTA Angelus (Angelus, Londrina, Brazil) (3), respectively. Both MTAs are based on Portland cement and thus contain other cement phases (ie, dicalcium silicate and tricalcium aluminate) (1-3). Biodentine contains $80 \%$ tricalcium silicate (3); the amount present in Bioaggregate has never been reported.

Hydration of tricalcium silicate in Portland cement and the materials derived from Portland produce calcium silicate hydrate gel, calcium hydroxide, and unreacted tricalcium silicate (4). The hydration of tricalcium silicate cement is similar to that of Portland cement (5). The calcium hydroxide produced as a reaction byproduct is responsible for the material bioactivity (6-8).

The bioactivity of tricalcium silicates has led to a wider use of the material with the development of root canal sealers. MTA Fillapex (Angelus, Londrina, Brazil) was among the first sealers based on MTA. Although several publications report physical $(9,10)$, chemical, and biological (11-13) properties of MTA Fillapex, little is known of its composition and hydration. The material has been shown to be bioactive (14). MTA Fillapex is composed of $40 \%$ MTA (tricalcium silicate, dicalcium silicate, tricalcium aluminate, and calcium oxide), which is present in Paste $\mathrm{B}$, together with silica fume, titanium dioxide, pentaerythritol rosinate, and p-Toluenesulfonamide. Paste A is composed of methyl salicylate, butylene glycol, colophony, bismuth trioxide, and silica fume (15).

Another sealer recently introduced, which is based on tricalcium silicate, is EndoSequence BC Sealer (Brasseler, Savannah, GA). It is a premixed ready-to-use injectable bioceramic cement paste developed for permanent root canal filling and sealing applications. The composition of EndoSequence BC Sealer as described by the manufacturer includes zirconium oxide, calcium silicates, calcium phosphate monobasic, calcium

From the Departments of * Restorative Dentistry, Faculty of Dental Surgery, and ${ }^{\ddagger}$ Physics, Faculty of Science, University of Malta, Msida, Malta; and ${ }^{\dagger}$ EM Douai, LGCgE-GCE, Douai, France.

Address requests for reprints to Prof Josette Camilleri, Faculty of Dental Surgery, Department of Restorative Dentistry, University of Malta, Medical School, Mater Dei Hospital, Msida MSD 2090, Malta. E-mail address: josette.camilleri@um.edu.mt

0099-2399/\$ - see front matter

Copyright (๑) 2015 American Association of Endodontists.

http://dx.doi.org/10.1016/j.joen.2014.09.015 
hydroxide, filler, and thickening agents (16). EndoSequence BC Sealer exhibited adequate physical properties (10) in accordance with ISO 6876:2012 specifications (17). The setting time was comparable with MTA Fillapex (2.7 hours). The material is premixed and can only set in the presence of moisture derived from the root canal $(10,16)$. Calcium ion release was greater than that reported for AH Plus (18). Compared with Biodentine and white MTA, EndoSequence BC Sealer showed less calcium ion release and did not show calcium and silicon incorporation as deeply inside the human root canal dentin when immersed in phosphate buffered saline for up to 90 days (19). It was shown to be biocompatible (20).

The interaction of tricalcium silicate-based sealers with tissue fluids and dentinal fluid results in the formation of mineral tags $(7$, 8). The exchange of calcium and silicon from the material to dentin has been shown (19). The reaction of calcium ions leached in solution from the hydrating cement with phosphates from dental fluid results in the formation of calcium phosphate, thus leading to material bioactivity (8). Material bioactivity can only occur if cement hydration occurs. Cement hydration is limited in the absence of moisture and not possible in premixed materials such as EndoSequence BC Sealer, which relies on the presence of dentinal fluid for hydration.

The aim of this study was to characterize EndoSequence BC Sealer in contact with dentin using a dentin pressure model to simulate in vivo conditions. Other tricalcium silicate-based sealers (ie, MTA Fillapex and an experimental sealer recently introduced by Septodont [Septodont Sealer]) were also investigated and their interaction with dentin and tissue fluids compared with Apexit Plus (Ivoclar, Schaan, Lichtenstein), which is a calcium hydroxide-based sealer. The material hydration using the dentin pressure model was compared with hydration assessed in vitro in the presence of physiologic solution. Furthermore, the setting time, radiopacity, and leaching in physiologic solution were also assessed.

\section{Methods}

The materials used in this study included EndoSequence BC Sealer, MTA Fillapex, Septodont Sealer, and Apexit Plus.

\section{Characterization of Set Materials Immersed in Physiologic Solution}

Cylindric specimens measuring $10 \mathrm{~mm}$ in diameter and 2-mm high were prepared from each sealer type. Once set, the materials were immersed in Hank's balanced salt solution (HBSS) (H6648; Sigma-Aldrich, St Louis, M0) for 14 days at $37^{\circ} \mathrm{C}$. Material characterization was performed by scanning electron microscopy of polished sections and also by X-ray diffraction (XRD) analysis of powdered set materials.

\section{Scanning Electron Microscopy}

After removal from HBSS, the cylindric specimens were vacuum desiccated and embedded in cold cure resin (Epoxyfix; Struers $\mathrm{GmbH}$, Ballerup, Denmark). The materials were polished with progressively finer grits of diamond discs and polishing clots accompanied by diamond suspensions using an automatic polishing machine (Tegramin 20; Struers, Ballerup, Denmark). The specimens were mounted on aluminum stubs, carbon coated, and viewed under a scanning electron microscope (Zeiss MERLIN Field Emission SEM; Carl Zeiss NTS GmbH, Oberkochen, Germany). Scanning electron micrographs of the different material microstructural components at different magnifications in the back-scatter electron mode were captured, and energy-dispersive spectroscopy was performed.

\section{KRD Analysis}

The chemical composition of the root canal sealers was assessed by powder diffractometry. The sealers were prepared and allowed to set; after this, they were powdered using an agate mortar and pestle to perform phase analysis using XRD. The X-ray diffractometer (Bruker D8 Advance; Bruker Corp, Billerica, MA) in locked mode using $\mathrm{Cu}$ $\mathrm{K} \alpha$ radiation was set at $40 \mathrm{~mA}$ and $45 \mathrm{kV}$ from $10^{\circ}-60^{\circ} 2 \theta$ and the holder spun at $15 \mathrm{rpm}$. A step of $0.01^{\circ} 2 \theta$ and a step time of 0.8 seconds were used.

\section{Characterization of Set Materials after Placement in Dentin Pressure Setup}

In situ assessment of hydration was performed by setting up a fluid flow system using a liquid column to create $20 \mathrm{~cm}$ water pressure as shown in Figure 1. The pressure was selected as suggested by previous research on the hydraulic conductance present in the dentinal tubules (21-23). The fluid used in the system was HBSS. Because the fluid used inside the system was not water, the relative density of HBSS was calculated to set up a liquid column with HBSS that created the equivalent $20 \mathrm{~cm}$ water pressure. The relative density of HBSS was determined by using specific gravity bottles weighed empty and then weighed when filled with water and when filled with HBSS at $37^{\circ} \mathrm{C}$ to determine the relative density of HBSS. The experiment was performed in triplicate. The relative density of HBSS was estimated to be $0.9960 \mathrm{~g} / \mathrm{cm}^{3}$. Therefore, the liquid column was adjusted slightly to keep the same pressure generated by the 20 $\mathrm{cm}$ water pressure.

Single-rooted lower premolars freshly extracted for orthodontic purposes from patients aged 13-16 years were used for this study. The teeth were decoronated and their root length standardized to $10 \mathrm{~mm}$. The cementum was shaved off by means of high-speed burs. The roots were radiographed to check that an average of 2 -mm thickness of dentin was present. The canals were prepared chemomechanically using ProTaper (Dentsply Maillefer, Ballaigues, Switzerland) up to size F3 $1 \mathrm{~mm}$ short of the root apex, and irrigation with $10 \mathrm{~mL}$ sodium hypochlorite followed by $5 \mathrm{~mL}$ EDTA and $5 \mathrm{~mL}$ distilled water was performed. The canals were dried with paper points and filled with the test sealers. The sealer was smeared along the root canal walls by means of rotary spiral fillers. The orifice and the root apex were blocked with resin composite so that the sealer did not come into contact with fluid through the orifices but just through the dentinal tubules. The obturated roots were placed horizontally in plastic tubing, which, in turn, were fit into the pressure system described previously. The roots were positioned horizontally so the fluid pressure was in contact with $2 \mathrm{~mm}$ of dentin. The whole setup was placed in an incubator at $37^{\circ} \mathrm{C}$ for 14 days. The roots were then retrieved, and the materials were characterized by scanning electron microscopy of polished longitudinal sections and XRD analysis of sealer retrieved from the canal space.

\section{Scanning Electron Microscopy}

The roots were superficially dried and were then embedded in cold cure resin and sectioned longitudinally along the long axis of the root. The sections were polished and were mounted on aluminum stubs, carbon coated, and viewed under the scanning electron microscope in the back-scatter electron mode. Energy-dispersive spectroscopic (EDS) analysis was performed at the interface and in the bulk of the material being tested.

\section{XRD Analysis}

Sealers used to obturate the root canal were retrieved from the canal space by cutting grooves longitudinally with a disc and 


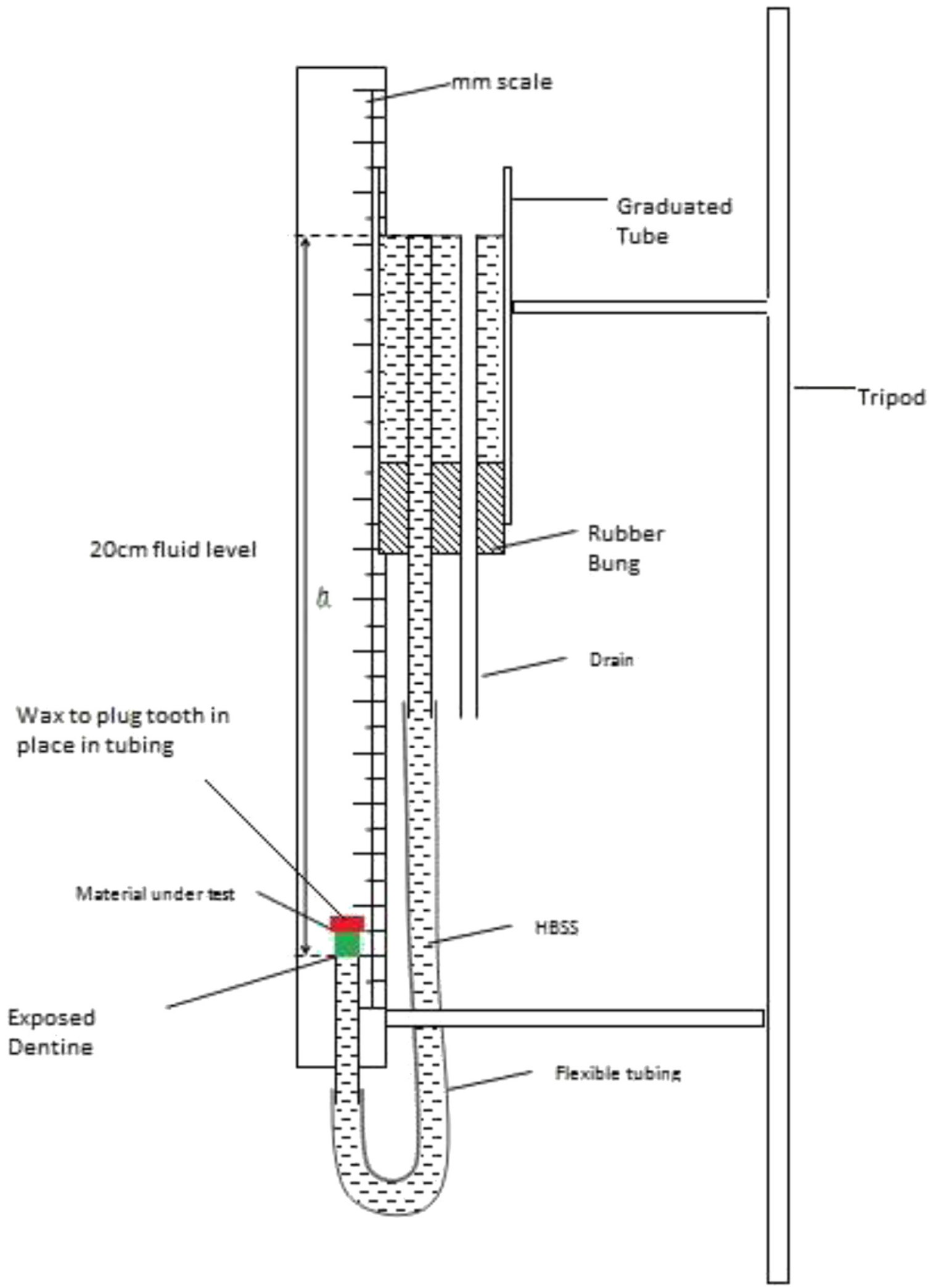

Figure 1. The fluid flow system setup.

splitting the root halves apart. Phase analysis was performed using glancing angle XRD analysis at a fixed angle of $3^{\circ}$. The X-ray diffractometer (Rigaku, Tokyo, Japan) using $\mathrm{Cu} \mathrm{K} \alpha$ radiation was set at
$40 \mathrm{~mA}$ and $45 \mathrm{kV}$ from $10^{\circ}-60^{\circ} 2 \theta$ with a sampling width of $0.05^{\circ}$ and a scan speed of $1 \% \mathrm{~min}$. The other settings included divergent slits at $1 \mathrm{~mm}$, divergent height slit of $10 \mathrm{~mm}$, scintillator 


\section{Basic Research-Technology}
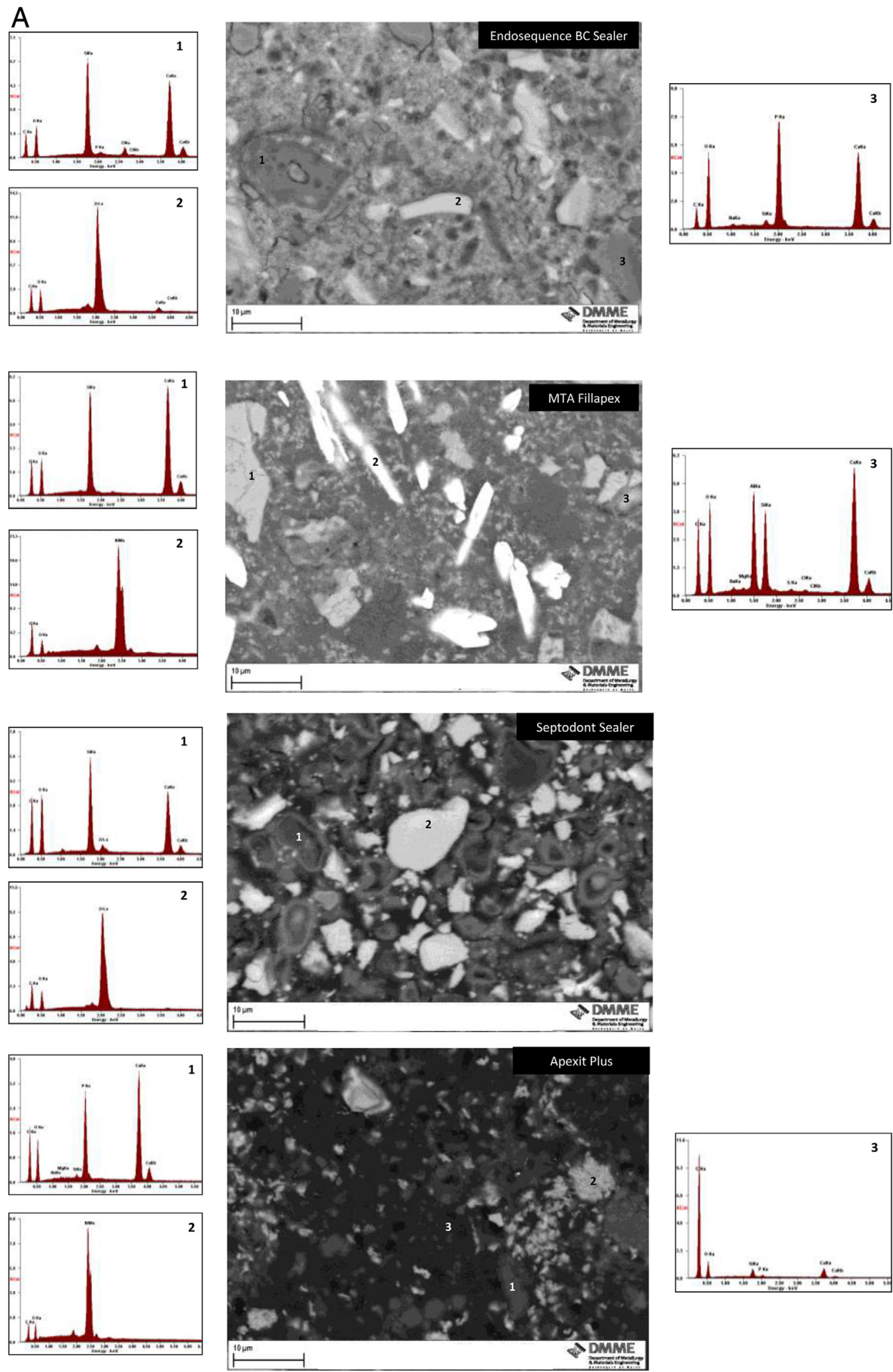

Figure 2. (A) Backscattered scanning electron micrographs of the test sealers $(5,000 \times$ magnification) and EDS analysis showing the main elements detected.

slit of $8 \mathrm{~mm}$, and receiver slit of $13 \mathrm{~mm}$. In addition, surface phase analysis of materials allowed to set in HBSS for 14 days was also performed. Phase identification was accomplished using search- match software using the International Centre for Diffraction Data database (International Centre for Diffraction Data, Newtown Square, PA). 
B
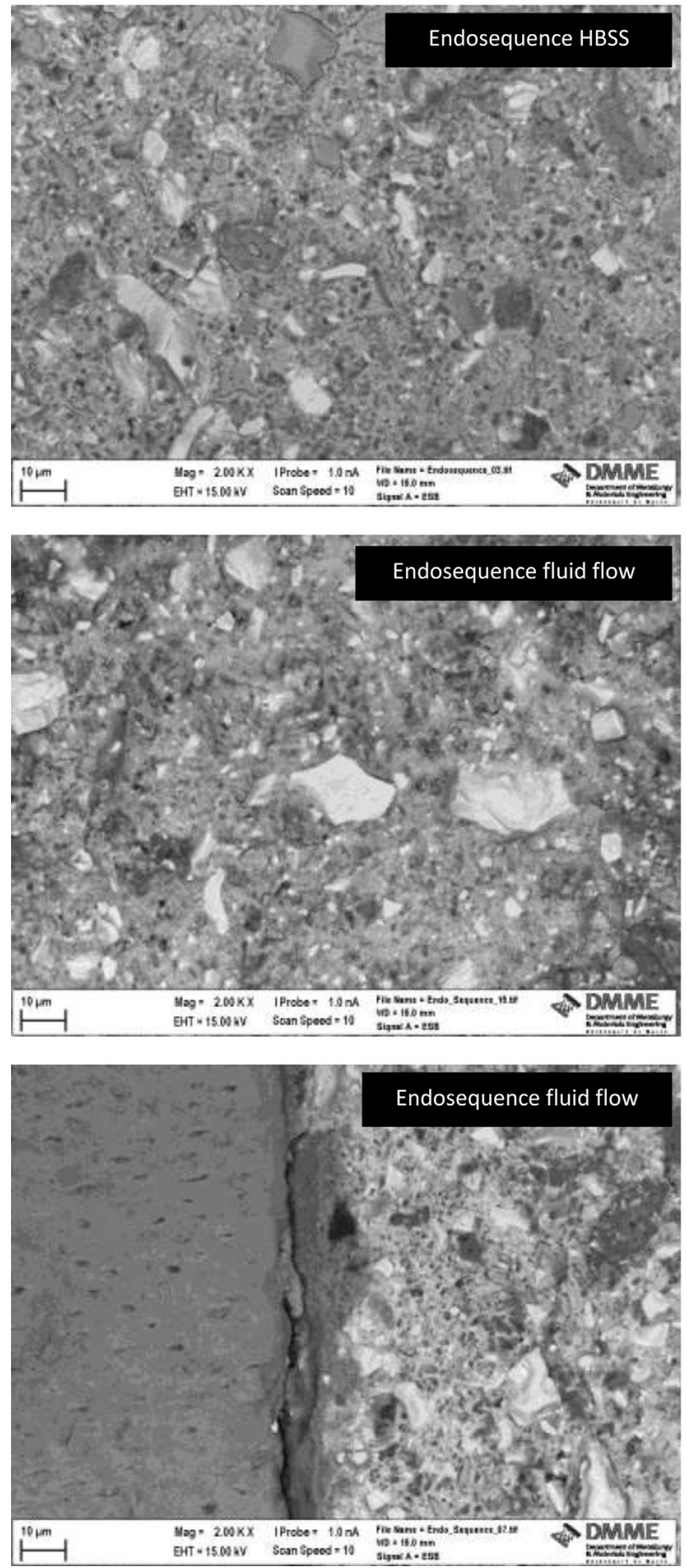
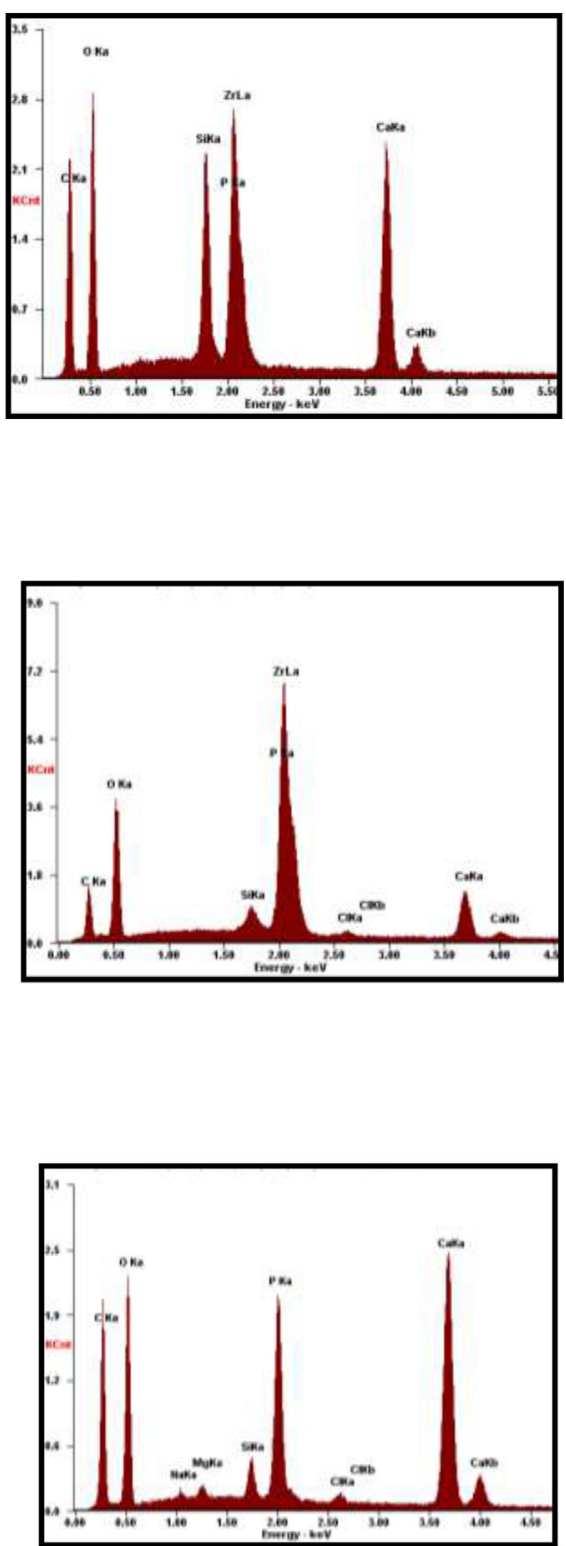

Figure 2. (continued). (B) Backscattered scanning electron micrographs and energy-dispersive spectroscopy of test materials immersed in HBSS or used as obturating materials.

\section{Assessment of Setting}

The setting time of the sealers was evaluated using the procedure set out in ISO 6876:2012 (17). The sealers were dispensed into molds measuring $10 \mathrm{~mm}$ in diameter and $2 \mathrm{~mm}$ in height. A stopwatch was started, and the molds were immediately placed in an incubator at $37 \pm 1{ }^{\circ} \mathrm{C}$ immersed in HBSS or allowed to set in a dry environment. Testing for setting was done using a modified Vicat apparatus consisting of a weighted needle having a round cross-section side of $2 \pm 0.1 \mathrm{~mm}$ with a total mass of $100 \pm 0.5 \mathrm{~g}$. The sealers were considered to have set when the needle was lowered gently onto the material surface and did not leave a complete indentation on the sample.
The setting time was also assessed on materials retrieved from the dentin pressure system. The roots were retrieved from the experimental setup, and grooves were cut on their mesial and distal surfaces. The teeth were split longitudinally to expose the sealer used to obturate the root canal. A Vicat indenter with a 100-g load was used to assess the setting of the sealers in situ.

\section{Assessment of Radiopacity}

Radiopacity evaluation of the set sealers was performed using ISO 6876:2012 recommendations (17). Three specimens measuring $10 \pm 1 \mathrm{~mm}$ in diameter and $1 \pm 0.1 \mathrm{~mm}$ in thickness were used. The specimens were radiographed by placing them directly on a 

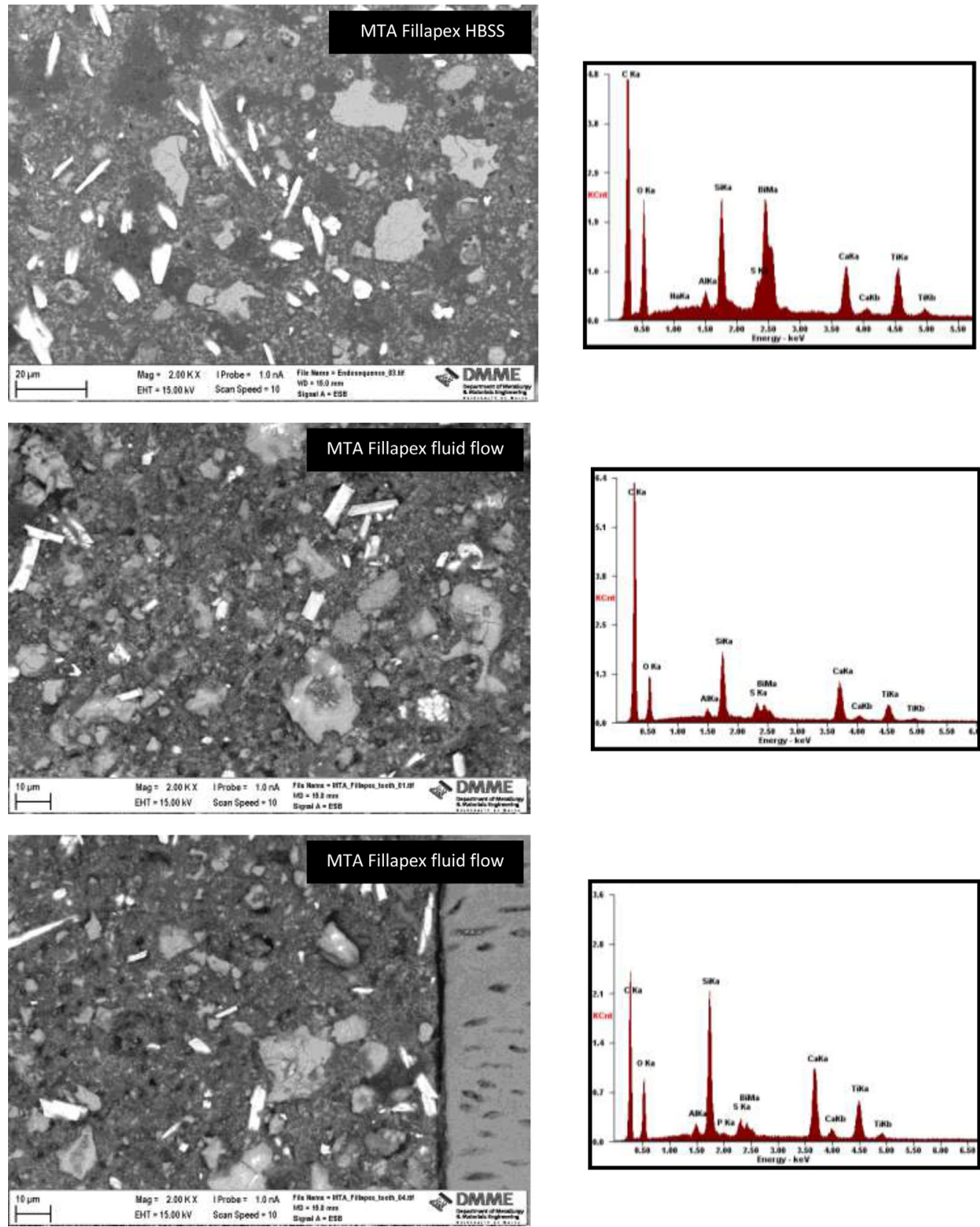

Figure 2. (continued).

photostimulable phosphor plate adjacent to a calibrated aluminum step wedge (Everything X-ray, High Wycombe, UK) having 3-mm increments. A standard X-ray machine (GEC Medical Equipment Ltd, Middlesex, UK) was used to irradiate $\mathrm{X}$-rays onto the specimens using an exposure time of 1.60 seconds at $10 \mathrm{~mA}$, tube voltage of $65 \pm 5 \mathrm{kV}$, and a cathode target film distance of $300 \pm 10 \mathrm{~mm}$. The radiographs were processed (Clarimat 300; Gendex Dental Systems, Medivance Instruments Ltd, London, UK), and a digital image of the radiograph was obtained. The gray pixel value on the radiograph of each step in the step wedge was determined using an imaging program (Adobe Photoshop; Adobe, San Jose, CA), and a graph of thickness of aluminum versus gray pixel value on the radiograph was then plotted with the best-fit logarithmic trend line. The equation of the trend line gave the gray pixel value of an object on the image as a function of the object's thickness in millimeters of aluminum. This equation was inverted to express the object's thickness as a function of its gray pixel value on the radiograph. The gray pixel values of the specimens were then determined, and the equivalent radiopacity was expressed in millimeters of aluminum.

\section{Assessment of Leaching}

The assessment of leaching of the test materials was performed using inductively coupled plasma on leachate recovered from specimens immersed in $5 \mathrm{~mL}$ HBSS for 14 days. The leachate was assessed for calcium, silicon, zirconium, phosphorus, and bismuth. Ion release was calculated, taking into consideration the sample size and volume of solution used for each specimen. A blank HBSS solution was also analyzed to calculate the ion content in the soaking solution without any specimen immersed in it to have a baseline. 

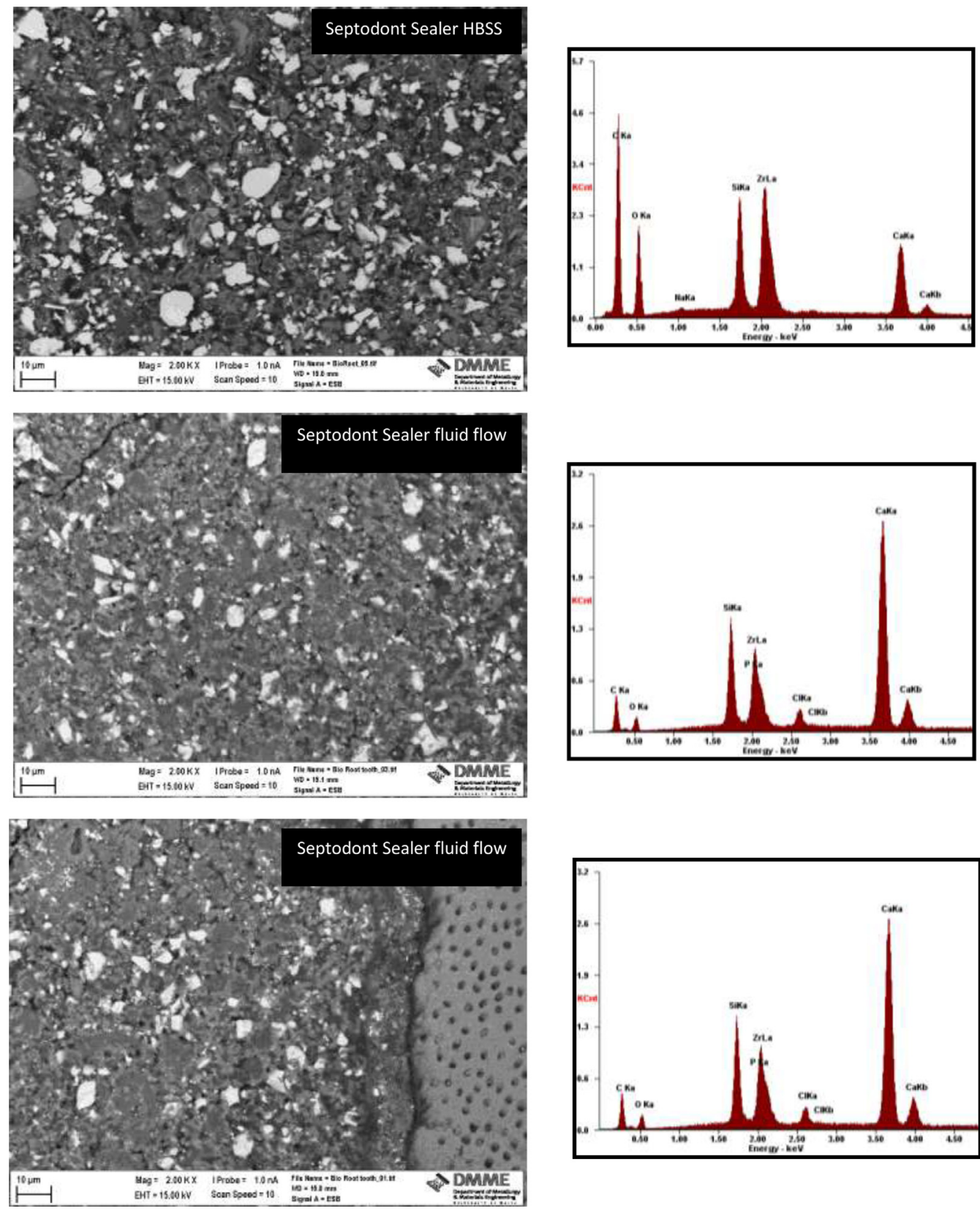

Figure 2. (continued).

\section{Statistical Analysis}

The data were evaluated using Statistical Package for the Social Sciences software (PASW Statistics 18; SPSS Inc, Chicago, IL). Parametric tests performed as Kolmogorov-Smirnov tests on the results indicated that the data followed a normal distribution. Analysis of variance with $P=.05$ and the Tukey post hoc test were used to perform multiple comparison tests of the results obtained.

\section{Resulits \\ Characterization of Set Materials Immersed in Physiologic Solution}

The scanning electron micrographs of the polished sections of the hydrated materials immersed in HBSS at 5,000 $\times$ magnification with EDS analysis of each component are shown in Figure $2 A$. The powder
X-ray diffractograms showing the phase analysis of the test sealers are shown in Figure $3 A$.

The EndoSequence BC Sealer exhibited a very dense matrix with minimum porosity. Particles rich in zirconium were interspersed within the cement particles (having a calcium and silicon elemental composition). Furthermore, rectangular particles rich in calcium and phosphorus were also detected (Fig. 2A). The phase analysis (Fig. 3A) showed peaks for tricalcium silicate, calcium phosphate, zirconium oxide, and calcium hydroxide. The MTA Fillapex exhibited a porous matrix interspersed with cement and bismuth-rich particles (Fig. 2A). Tricalcium silicate was shown on XRD analysis together with the bismuth oxide and silicon oxide (Fig. $3 A$ ). Aluminum and sulfur-rich particles were evident, indicating that the cement was a Portland-type cement (Fig. 2A). The cement particles did not show any hydration, and no calcium hydroxide peak ( $18^{\circ} 2 \theta$ using a copper tube) was shown on XRD analysis. The Septodont Sealer was composed mainly of cement, which 

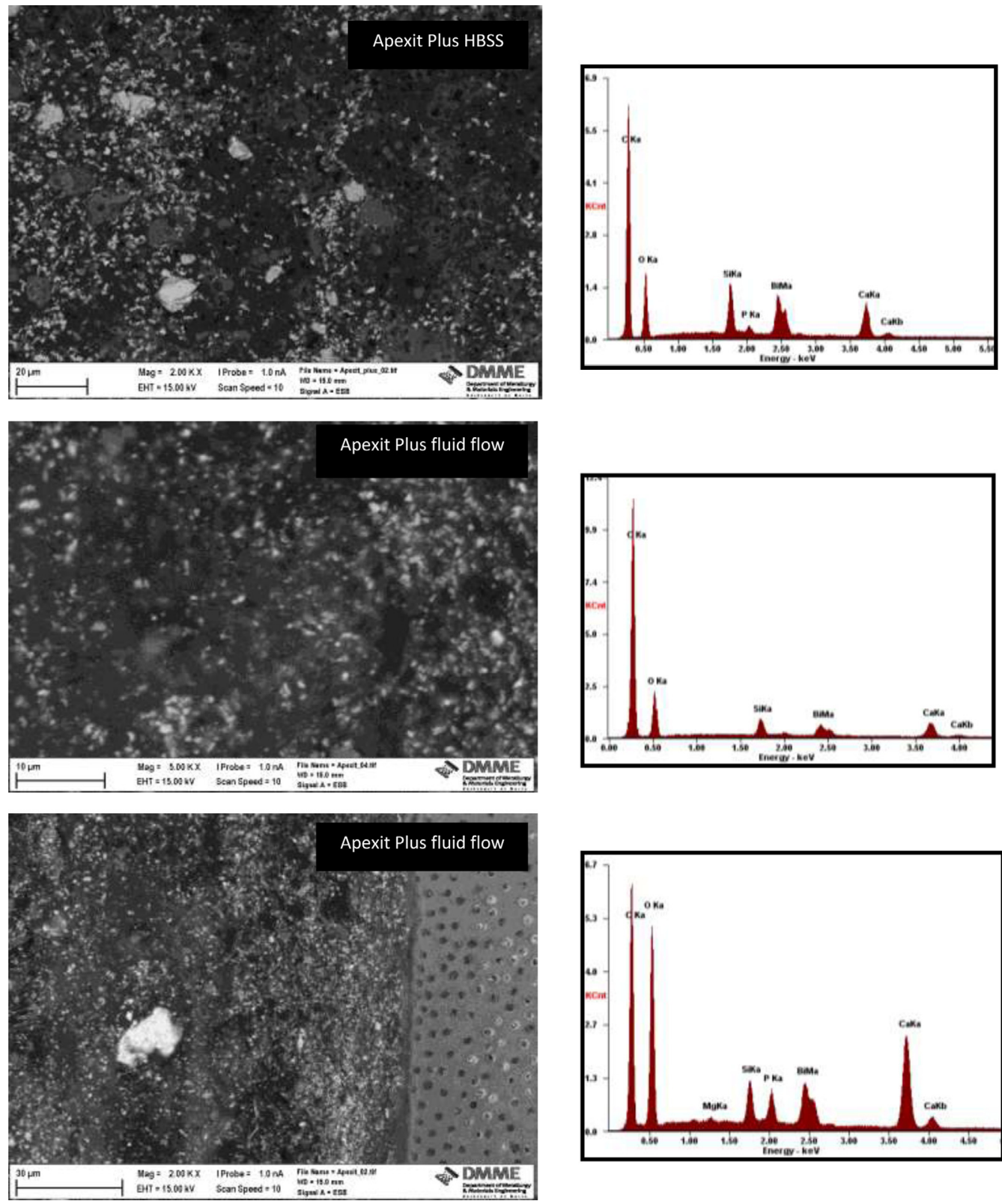

Figure 2. (continued).

showed a high degree of hydration (reaction rims present around the cement particle) and particles rich in zirconium (Fig. $2 A$ ). The XRD analyses showed the presence of zirconium oxide and a predominant calcium hydroxide peak, which was higher than that exhibited by EndoSequence BC Sealer. The tricalcium silicate phase was not present, indicating the fast reaction of this phase to form an amorphous calcium silicate hydrate (Fig. $3 A$ ). Apexit Plus exhibited a resin matrix and particles rich in calcium and phosphorus as well as other bismuth-rich particles (Fig. 2A). XRD analysis showed the presence of bismuth carbonate, bismuth oxide, and some calcium hydroxide (Fig. $3 A$ ).

\section{Characterization of Set Materials after Placement in Dentin Pressure Setup}

The scanning electron micrographs and EDS plots of the polished sections of the test sealers immersed in HBSS at $2.5 \mathrm{~K} \times$ magnification compared with micrographs and analyses of tooth to material interface and bulk material from teeth kept in a fluid pressure system for 14 days are shown in Figure $2 B$. Surface X-ray diffractograms of materials stored in HBSS are superimposed on diffractograms of the material hydrated in the tooth kept in the fluid pressure setup (Fig. $3 B$ ).

All the test sealers exhibited some degree of phosphate-forming ability at the interface in the tooth kept in the fluid pressure setup (Fig. 2B, EDS analysis). In EndoSequence BC Sealer and Septodont Sealer, the phosphate peak superimposed the zirconium peak. Because of this, it was difficult to assess the presence of phosphorus in these test materials. MTA Fillapex and Apexit Plus exhibited a phosphorus peak at the interface, but this was absent in the bulk of the material. The scanning electron micrographs showed no reaction rims around the cement particles for MTA Fillapex and EndoSequence BC Sealer. There were evident reaction rims in Septodont Sealer, which were more marked in the material immersed in HBSS and at the tooth to material interface rather than 

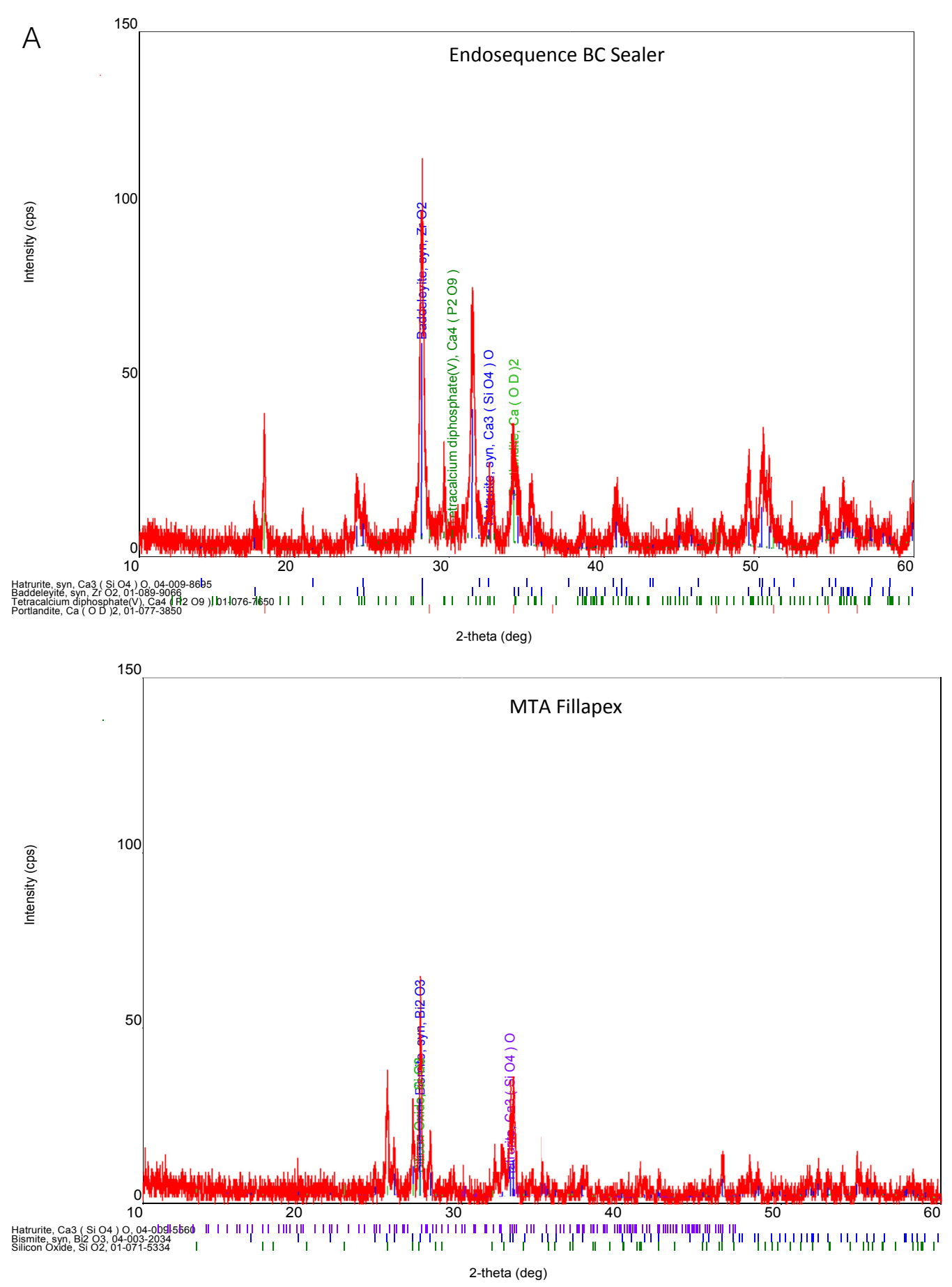

Figure 3. (A) Powder diffractograms of the test sealers showing the main phases present.

in the bulk of the material. Apexit Plus showed a denser aggregation of radiopacifier at the interface (Fig. $2 B$ ). The phosphorus peak at the interface was higher than that for the material immersed in HBSS.

XRD analysis of the material surface compared with that for the material retrieved from the root canal space is shown in Figure $3 B$. The EndoSequence BC Sealer exhibited identical plots for the material in solution and for the material retrieved from the tooth. The material in solution had a Portlandite (calcium hydroxide) peak, which was not present in the material retrieved from the root canal space (marked with a star on the XRD plot). This feature was also exhibited by Septo- dont Sealer. No evidence of formation of calcium hydroxide was found in the phase analyses for MTA Fillapex. Both the Septodont Sealer and Apexit Plus exhibited an additional calcium phosphate peak in the material immersed in HBSS (marked with an arrow), which was not evident in the material in contact with the tooth.

\section{Assessment of Setting}

Indentation in situ showed that the sealers had set because no indentation marks were left on the material surface after the tooth 

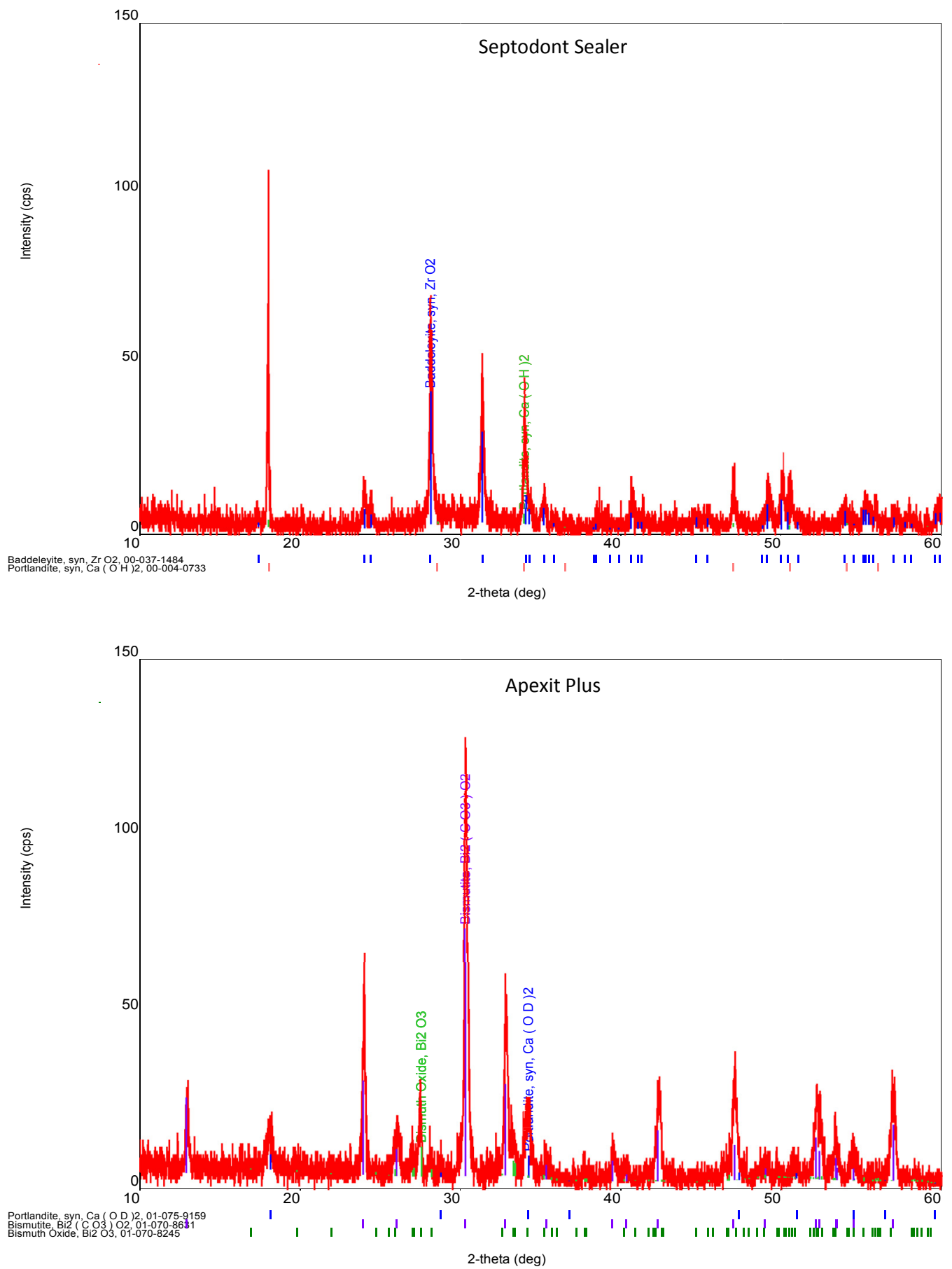

Figure 3. (continued). (B) Surface XRD analysis of test sealers used to obturate the root canals compared with the test sealers stored in HBSS for 14 days.

was split longitudinally. The assessment of the setting time in accordance with ISO 8676:2012 (17) is shown in Table 1. The EndoSequence BC Sealer failed to set when stored dry, which is in accordance with the manufacturer's instructions. The MTA Fillapex exhibited indentation marks for over 3 days when stored dry; thus, it could not be classified as having completely set. Both EndoSequence BC Sealer and MTA Fillapex set when immersed in HBSS. There was no statistical difference in the setting time of these sealers $(P>.05)$. On the contrary, Septodont Sealer set in a relatively short period of time in a dry environment. The setting time was extended by contact with physiological solu- tion $(P<.01)$. Apexit Plus showed the shortest setting time when immersed in HBSS. There was no difference in the material setting $(P>.05)$ when dependent on the environmental conditions.

\section{Assessment of Radiopacity}

All the sealers tested exhibited radiopacity higher than the 3-mm aluminum thickness (Fig. 4) as suggested by ISO 6876:2012 (17). Endsequence, Septodont Sealer, and Apexit Plus showed a higher radiopacity than MTA Fillapex $(P<.05)$. 

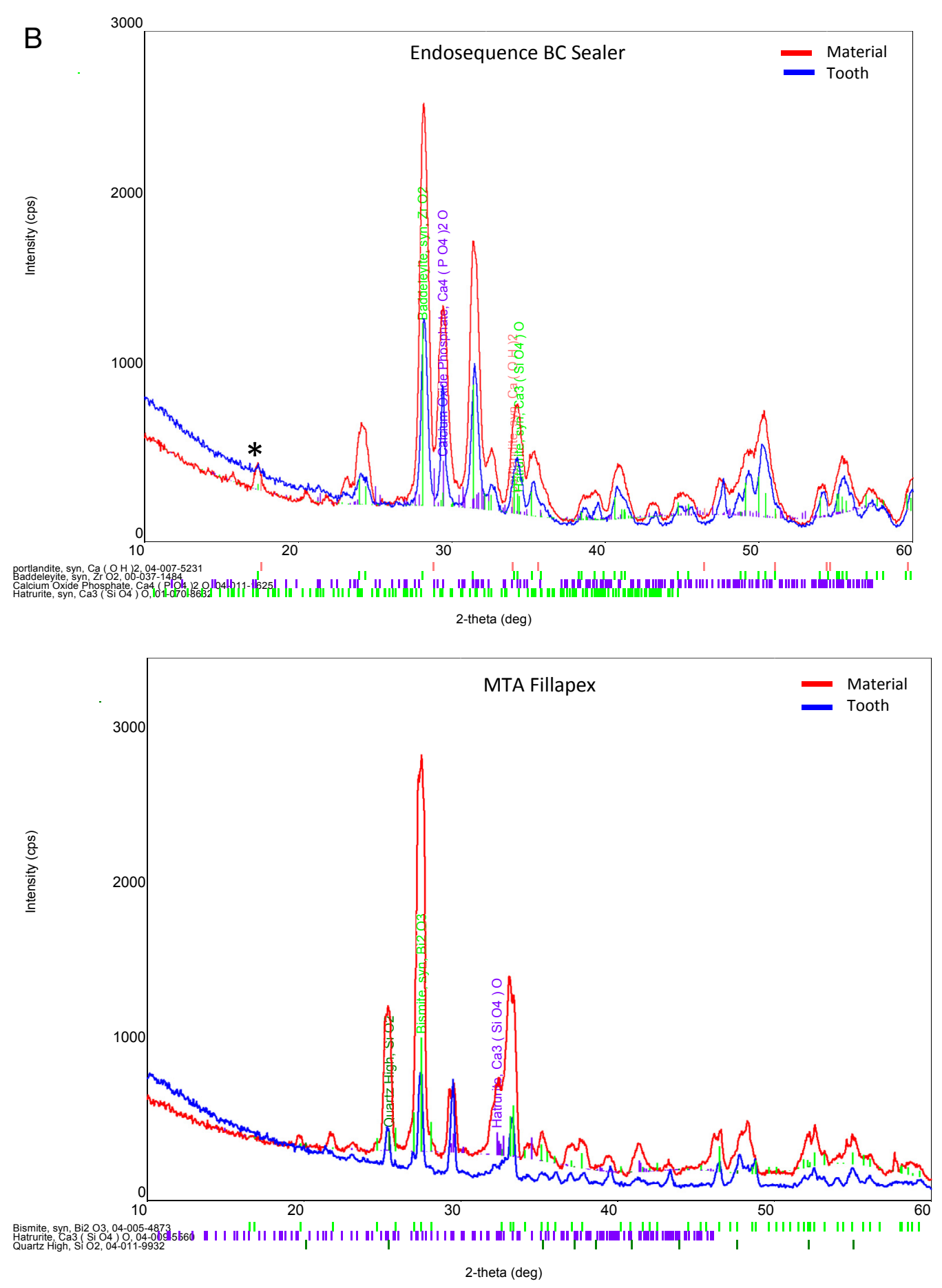

Figure 3. (continued).

\section{Assessment of Leaching}

The leachate analysis results from the various materials in solution are shown in Table 2. All the materials exhibited leaching of calcium. The highest leaching was exhibited by the Septodont Sealer followed by EndoSequence BC Sealer. Zirconium in Septodont Sealer was stable with no leaching, whereas some leaching of zirconium was evident in EndoSequence BC Sealer. Bismuth was leached from both MTA Fillapex and Apexit Plus. The phosphorus leaching varied with the highest leaching exhibited by EndoSequence BC Sealer. MTA Fillapex exhibited a negative value, indicating that there was uptake of phosphorus from the solution rather than leaching.

\section{Discussion}

The materials used in this study were sealers based on tricalcium silicate compared with a calcium hydroxide-based sealer (Apexit Plus). Tricalcium silicate is the main phase present in Portland cement and MTA. MTA and Portland cement are hydraulic materials that depend on environmental moisture to improve the 

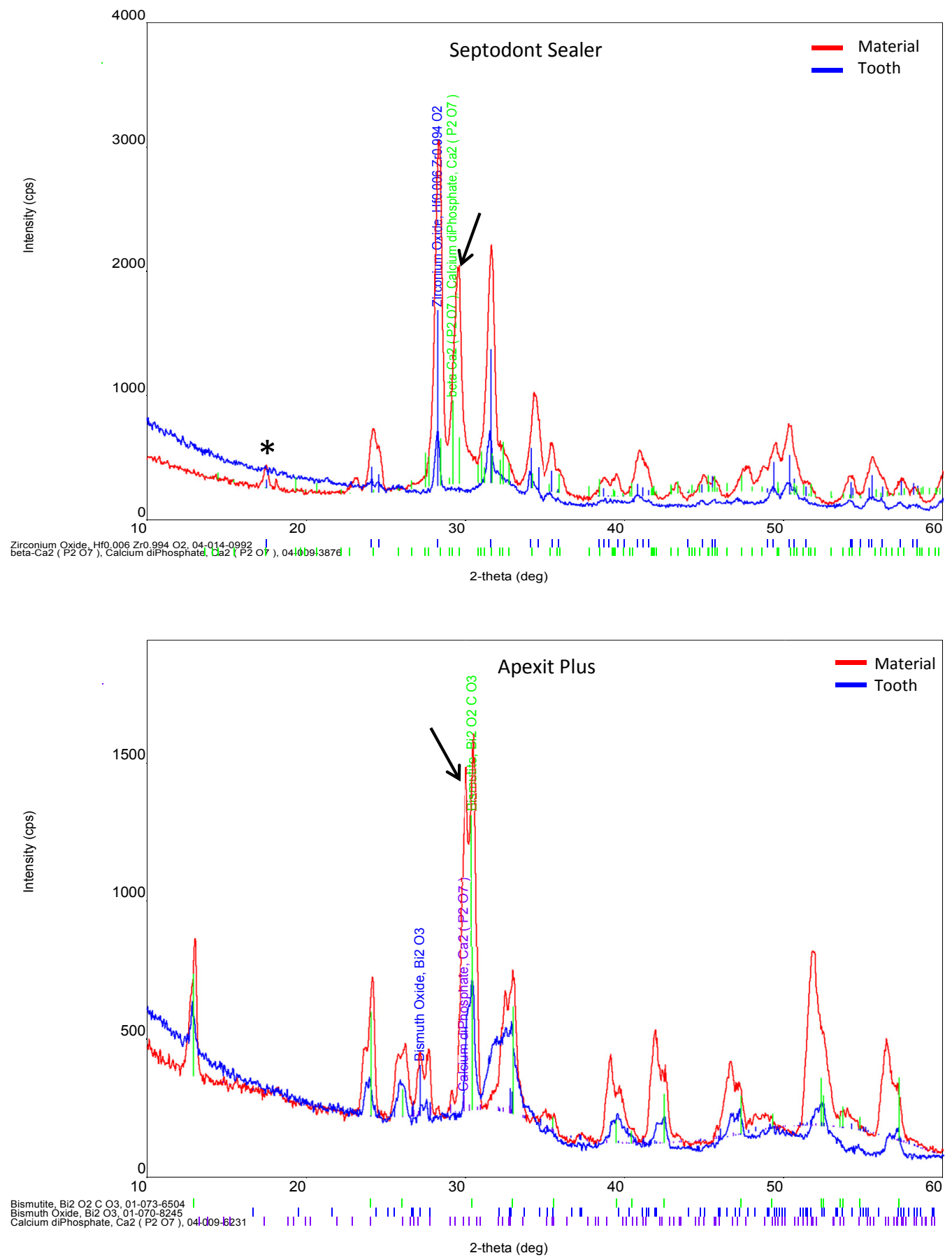

Figure 3. (continued).

properties of the set material. The setting of MTA and tricalcium silicate cement-based materials is impaired in the presence of synthetic tissue fluids (24-26). Synthetic tissue fluids contain phosphate ions and glucose, both of which are implicated in the retardation of setting of tricalcium silicate-based materials. Although the failure of setting has been reported in vitro, there is no evidence that this occurs in vivo.

MTA Fillapex is based on the MTA formula with a Portland cement base (containing an aluminum phase as opposed to other materials based on tricalcium silicate that lack the aluminum phase) and bismuth oxide radiopacifier including other additives like silicon oxide and a resin matrix. This can be seen from the scanning electron microscopy and XRD analyses. The Septodont Sealer and EndoSequence BC Sealer were both composed of tricalcium silicate and zirconium oxide. The EndoSequence BC Sealer also contained a calcium phosphate phase (shown in XRD scans and calcium and phosphorus were present in EDS analysis). The Septodont Sealer is supplied as a powder and liquid, which are mixed, and hydration of the cement then follows. On the other hand, EndoSequence BC Sealer is supplied in premixed form, which is syringed and can only hydrate in contact with dentinal fluid (16). The manufacturer's recommendations state that EndoSequence BC Sealer requires moisture to set. These were proved correct because the 
TABLE 1. Setting Time of Test Sealers Immersed in Physiological Solution or Allowed to Set Dry at $37^{\circ} \mathrm{C}( \pm$ Standard Deviation $)$

\begin{tabular}{lcc}
\hline & \multicolumn{2}{c}{ Setting time/h } \\
\cline { 2 - 3 } \multicolumn{1}{c}{ Sealer tested } & Immersed in HBSS & Dry \\
\hline EndoSequence BC Sealer & $22.3 \pm 0.9$ & Failed to set \\
MTA Fillapex & $19.3 \pm 0.6$ & Failed to set \\
Septodont Sealer & $15.8 \pm 0.6$ & $1.3 \pm 0.05$ \\
Apexit Plus & $5.47 \pm 0.8$ & $3.22 \pm 0.1$ \\
\hline
\end{tabular}

HBSS, Hank's balanced salt solution.

material failed to set when in a dry environment. The setting time of EndoSequence BC Sealer has been reported to be comparable with that of MTA Fillapex with a setting time of about 2.7 hours (10). This is in contrast with the results obtained in the current study in which both materials failed to set in a dry environment (partial set recorded for MTA Fillapex), whereas a setting time of over 19 hours was shown for both materials when immersed in physiological solution. A recent investigation of the setting of EndoSequence BC Sealer reported a setting time of at least 168 hours in the presence of water (27). On the other hand, Septodont Sealer exhibited properties similar to MTA and Portland cement-based materials. The setting time was extended in contact with physiological solution. Septodont Sealer is a novel sealer, and no data on its physical properties are currently available.

Although MTA Fillapex is based on Portland cement, no hydration byproducts were shown to be present in the cement matrix and no Portlandite peak was visible on the X-ray diffractogram. This is in contrast to the Septodont Sealer and EndoSequence BC Sealer. Both materials exhibited a Portlandite peak on XRD. The Septodont Sealer exhibited a stronger peak than EndoSequence BC Sealer. Indeed, the tricalcium silicate peaks in the region of $32^{\circ} 2 \theta$ were completely obliterated in Septodont Sealer. This is indicative of a high material reaction rate where most of the tricalcium silicate is converted to calcium silicate hydrate, which is amorphous and cannot be discerned on the X-ray diffractogram even after 14 days of hydration. The higher reaction rate of Septodont Sealer is also evident from the calcium ion leaching, which is double for Septodont Sealer compared with EndoSequence BC Sealer.
The dentin permeability model was set up in order to investigate the setting of the materials in conditions similar to in vivo ones. Most of the research performed on material setting is in vitro where large volumes of liquid are used to store the materials. These conditions are not valid in vivo where minimal amounts of fluids are available in contact with the materials. An equivalent of $20 \mathrm{~cm}$ water pressure was set up using synthetic tissue fluid as solution in contact with the materials under study. The $20 \mathrm{~cm}$ water pressure was chosen in accordance with studies investigating the hydraulic conductance of dentin (21-23). Dentin permeability is mainly caused by the dentinal tubules present. Permeability in dentin can be reduced by the apposition of tertiary dentin, the deposition of crystalline calcium phosphate, or the presence of the smear layer and coagulation products (28). Hydraulic conductance is dependent on fluid flow, the surface area of the dentin, and the hydrostatic pressure applied over a period of time (29). A dentinal pressure of $20 \mathrm{~cm}$ water was used to induce conductive and diffusive transport in the test material. The rationale behind this is based on the hydraulic conductance equation. Tests show that the hydraulic conductance was taken to range between $1.5 \times 10^{-3}$ and $8.97 \times 10^{-3} \mu \mathrm{L} \bullet \mathrm{cm}^{2} \bullet \min \bullet \mathrm{cmH}_{2} \mathrm{O}$. The surface area of dentin quoted in previous literature was $0.1-0.2 \mathrm{~cm}^{2}$ over a time period ranging between 30 and 120 minutes $(22,23)$. Studies quoting Pashley's work all quote the $20 \mathrm{~cm}$ water $(21,29)$. Based on the literature available, it was concluded that with a pressure of $20 \mathrm{~cm}$ water, one could detect, analyze, and localize the fluid flow of individual dentinal tubules from the images created $(22,23)$.

In previous research investigating the setting of materials based on tricalcium silicate in contact with different solutions, a delayed setting or no setting has been reported $(24-26,30,31)$. In all this literature, a large quantity of fluid was used to conduct the experiment. Thus, the findings are not valid clinically. With the current dentin pressure setup, the setting of root canal sealers could be monitored in a clinically relevant scenario, thus mimicking the in vivo scenario. The fluid available inside the root canal allowed the EndoSequence BC Sealer to set because this material can only set in the presence of moisture as has been verified in the current study. The sealer inside the tooth did not exhibit the formation of calcium hydroxide. This

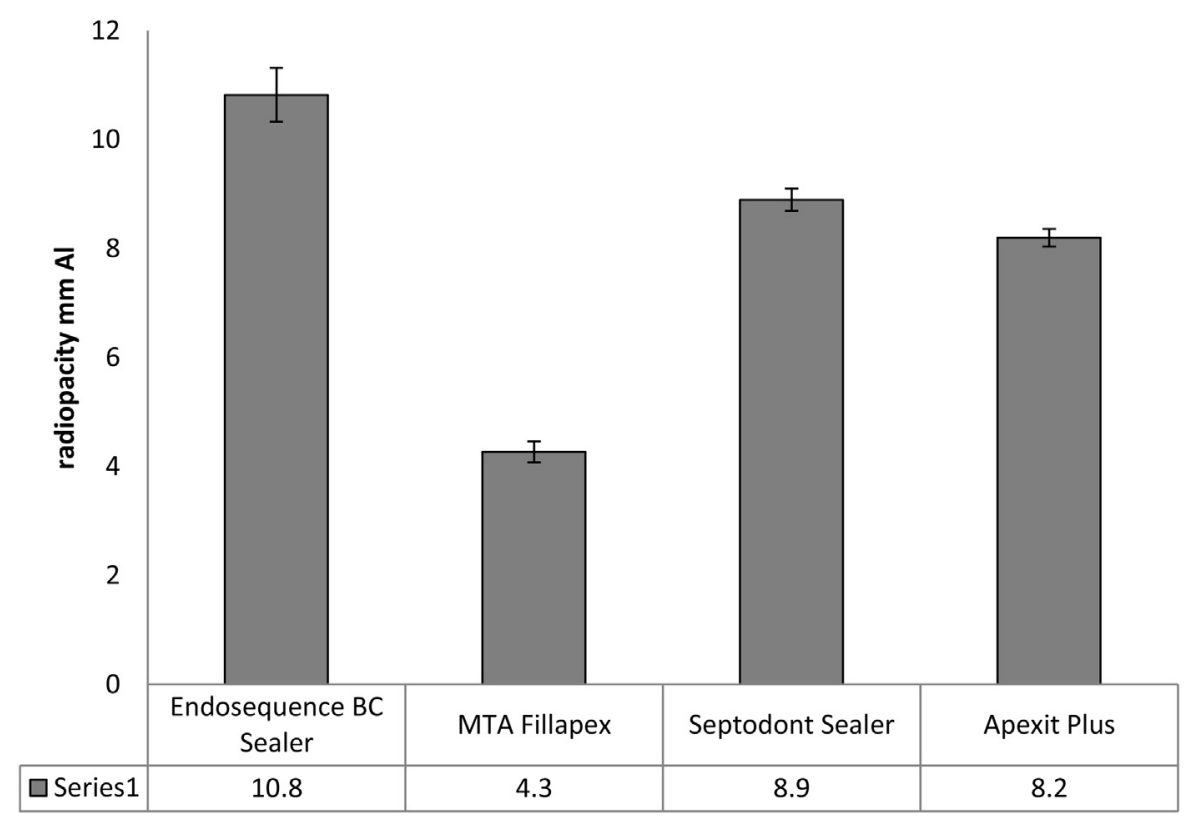

Figure 4. The radiopacity of the test sealers. 
TABLE 2. Ion Leaching in Milligrams per Gram Measured by ICP-MS

\begin{tabular}{lcccc}
\hline & & Material & \\
\cline { 2 - 4 } & EndoSequence BC Sealer & MTA Fillapex & Septodont Sealer & Apexit Plus \\
\hline Calcium & 14,026 & 3358 & 29,712 & 28 \\
Silicon & 135 & 610 & - & - \\
Zirconium & 15 & -806 & - & 16 \\
Bismuth & - & -221 & 54 \\
Phosphorus & 104 &
\end{tabular}

could have converted to calcium phosphate by the phosphates present in physiological solution. However, this could not be verified because the material contains a calcium phosphate phase. Phosphorus was leached in solution in higher quantities in EndoSequence BC Sealer compared with the other sealers tested. On the other hand, the Septodont Sealer, which does not include a calcium phosphate phase, did not exhibit the formation of calcium phosphate when it hydrated inside the root canal. However, this phase was present in the material placed in HBSS. The same was demonstrated for Apexit Plus. Thus, on immersing the materials in physiologic solution, one cannot predict the material hydration and setting behavior. Although it is assumed that tricalcium silicate-based materials are bioactive and interact with dentinal fluid to form mineral tags, this may not be happening in the clinical scenario. Therefore, the benefits of using a bioactive sealer are limited.

All the sealers exhibited adequate radiopacity in accordance with ISO 6876:2012 (17). MTA Fillapex had the lowest radiopacity compared with the other sealers. The radiopacity exhibited for EndoSequence BC Sealer was higher than that reported in a previous study (18) in which EndoSequence BC Sealer showed a radiopacity of $3.84 \mathrm{~mm} \mathrm{Al}$ as compared with $10.8 \mathrm{~mm} \mathrm{Al}$ reported in the current study.

\section{Conclusions}

Using the dentinal fluid pressure system resulted in an adequate flow of dentinal fluid that allowed the EndoSequence BC Sealer to set inside the root canal. Although the sealers tested were tricalcium silicate based, the hydration reaction and bioactivity in the presence of dentinal fluid were different to hydration in vitro. Thus, clinically, material bioactivity cannot be assumed.

\section{Acknowledgments}

The authors thank Dr Ralph Rawls, Mr Nicholas Gautier, and Dr Gilles Richard for the procurement of the materials and Ing James Camilleri of the Department of Metallurgy and Materials Engineering, Faculty of Engineering, University of Malta, Msida, Malta, for his technical expertise.

The authors deny any conflicts of interest related to this study.

\section{References}

1. Camilleri J. Characterization of hydration products of mineral trioxide aggregate. Int Endod J 2008;41:408-17.

2. Belío-Reyes IA, Bucio L, Cruz-Chavez E. Phase composition of ProRoot mineral trioxide aggregate by X-ray powder diffraction. J Endod 2009;35:875-8.

3. Camilleri J, Sorrentino F, Damidot D. Investigation of the hydration and bioactivity of radiopacified tricalcium silicate cement, Biodentine and MTA Angelus. Dent Mater 2013;29:580-93.

4. Taylor HFW. Cement Chemistry. London: Thomas Telford; 1997.

5. Camilleri J. Characterization and hydration kinetics of tricalcium silicate cement for use as a dental biomaterial. Dent Mater 2011;27:836-44.

6. Coleman NJ, Awosanya K, Nicholson JW. A preliminary investigation of the in vitro bioactivity of white Portland cement. Cem Concr Res 2007:37:1518-23.
7. Tay FR, Pashley DH, Rueggeberg FA, et al. Calcium phosphate phase transformation produced by the interaction of the portland cement component of white mineral trioxide aggregate with a phosphate-containing fluid. J Endod 2007;33: $1347-51$.

8. Reyes-Carmona JF, Felippe MS, Felippe WT. Biomineralization ability and interaction of mineral trioxide aggregate and white portland cement with dentin in a phosphatecontaining fluid. J Endod 2009;35:731-6.

9. Viapiana R, Flumignan DL, Guerreiro-Tanomaru JM, et al. Physicochemical and mechanical properties of zirconium oxide and niobium oxide modified Portland cement-based experimental endodontic sealers. Int Endod J 2014;47: 437-48.

10. Zhou HM, Shen $Y$, Zheng W, et al. Physical properties of 5 root canal sealers. J Endod 2013;39:1281-6.

11. Güven EP, Yalvaç ME, Kayahan MB, et al. Human tooth germ stem cell response to calcium-silicate based endodontic cements. J Appl Oral Sci 2013;21:351-7.

12. Yoshino P, Nishiyama CK, Modena KC, et al. In vitro cytotoxicity of white MTA, MTA Fillapex ${ }^{\circledR}$ and Portland cement on human periodontal ligament fibroblasts. Braz Dent J 2013;24:111-6.

13. Marques NC, Lourenço Neto N, Fernandes AP, et al. Rat subcutaneous tissue response to MTA Fillapex ${ }^{\circledR}$ and Portland cement. Braz Dent J 2013;24:10-4.

14. Salles LP, Gomes-Cornélio AL, Guimarães FC, et al. Mineral trioxide aggregate-based endodontic sealer stimulates hydroxyapatite nucleation in human osteoblast-like cell culture. J Endod 2012;38:971-6.

15. MTA Fillapex Endodontic Sealer. Angelus. Available at: http://www.angelusdental. com/img/arquivos/mta_fillapex_technical_profile_download.pdf. Accessed November 9, 2013.

16. Available at: http://www.brasselerusa.com/brass/assets/File/B_3114D_EndoSequence \%20BC\%20Sealer\%20DFU.pdf. Accessed January 10, 2014.

17. International Standards Organization. Dentistry: Root Canal Sealing Materials. ISO 6876; 2012

18. Candeiro GT, Correia FC, Duarte MA, et al. Evaluation of radiopacity, pH, release of calcium ions, and flow of a bioceramic root canal sealer. J Endod 2012;38:842-5.

19. Han L, Okiji T. Bioactivity evaluation of three calcium silicate-based endodontic materials. Int Endod J 2013;46:808-14.

20. Willershausen I, Callaway A, Briseño B, Willershausen B. In vitro analysis of the cytotoxicity and the antimicrobial effect of four endodontic sealers. Head Face Med 2011;10:7-15.

21. Ozok AR, Wu MK, Wesselink PR. The effects of post-extraction time on the hydraulic conductance of human dentine in vitro. Arch Oral Biol 2002;47:41-6.

22. Pashley DH, Thompson SM, Stewart FP. Dentine permeability: effects of the temperature on hydraulic conductance. J Dent Res 1983;62:956-9.

23. Pashley DH, Matthews WG. The effects of outward forced convective flow on the inward diffusion in human dentine in vitro. Arch Oral Biol 1993;38:577-82.

24. Camilleri J, Formosa L, Damidot D. The setting characteristics of MTA Plus in different environmental conditions. Int Endod J 2013;46:831-40.

25. Formosa LM, Mallia B, Camilleri J. The effect of curing conditions on the physical properties of tricalcium silicate cement for use as a dental biomaterial. Int Endod J 2012;45:326-36.

26. Kim Y, Kim S, Shin YS, et al. Failure of setting of mineral trioxide aggregate in the presence of fetal bovine serum and its prevention. J Endod 2012;38:536-40.

27. Loushine BA, Bryan TE, Looney SW, et al. Setting properties and cytotoxicity evaluation of a premixed bioceramic root canal sealer. J Endod 2011;37:673-7.

28. Pashley DH, Galloway SE, Stewart F. Effects of fibrinogen in vivo on dentine permeability in the dog. Arch Oral Biol 1984;29:725.

29. Camps J, Martin P, Ladeque P, et al. Influence of tooth cryopreservation on human dentin permeability. Dent Mater 1994;10:210-4.

30. Budig CG, Eleazer PD. In vitro comparison of the setting of dry ProRoot MTA by moisture absorbed through the root. J Endod 2008;34:712-4.

31. Charland T, Hartwell GR, Hirschberg C, Patel R. An evaluation of setting time of mineral trioxide aggregate and EndoSequence Root Repair Material in the presence of human blood and minimal essential media. J Endod 2013;39: 1071-2. 